\title{
A disseminação do Pensamento Computacional por docentes do Ensino Fundamental I: Relatos de Experiências e Discussões
}

\author{
Suéllen Rodolfo Martinelli ${ }^{1}$, Tiemi Christine Sakata ${ }^{1}$ \\ ${ }^{1}$ Departamento de Computação de Sorocaba - Universidade Federal de São Carlos \\ CEP 18052-780 - Sorocaba - SP - Brasil \\ suellen.r.martinelli@gmail.com, tiemi@ufscar.br
}

\begin{abstract}
This paper describes experience reports about Computational Thinking (CT) activities mediated by teachers of Elementary School. We provided a continuing education course for these teachers aiming to introduce unplugged and plugged activities that integrate CT with other curricular components. The analysis os the 33 practices produced was supported by a qualitative and descriptive approach. Most of them were associated with algorithmic reasoning and used unplugged activities.
\end{abstract}

Resumo. Este trabalho expõe relatos de experiências de práticas sobre Pensamento Computacional aplicadas por docentes do Ensino Fundamental I. Foi ministrada uma formação continuada sobre o assunto, com a condução de atividades desplugadas e plugadas, que integram conteúdos dos Componentes Curriculares. $O$ estudo foi apoiado por uma abordagem qualitativa e de caráter descritivo, sendo as 33 atividades produzidas em curso pelos participantes, o principal meio de análise. Houve maior aderência dos docentes por atividades desplugadas e, em sua maioria, associadas ao raciocínio algorítmico.

\section{Introdução}

Sabe-se, atualmente, que os conhecimentos relacionados à Computação são tão importantes para a vida na sociedade contemporânea, quanto aqueles associados às demais áreas, como Matemática, Linguagens e Ciências [SBC 2017]. Anterior aos conhecimentos que propiciam a fluência do indivíduo em um mundo digital, é preciso estimular nas crianças, desde o Ensino Básico, um raciocínio analítico e sistemático. O Pensamento Computacional (PC), do inglês Computational Thinking, é definido como um conjunto de habilidades centradas em fundamentos da Ciência da Computação e que auxiliam na interpretação e solução de problemas de todas as áreas do conhecimento, sem ser necessário o emprego de recursos digitais para esse fim. A competência de se "pensar computacionalmente" requer a capacidade de simplificar problemas, desenvolver o raciocínio lógico, analisar fatos, reduzir problemas em partes menores e gerenciáveis, entre outros procedimentos mentais, empregados na resolução de problemas [Wing 2006].

Países como Inglaterra, Irlanda, Portugal e Israel já possuem currículos próprios voltados especificamente para o ensino do PC [Balanskat and Engelhardt 2015], além de organizações como a Computer Science Teachers Association (CSTA), a Association for Computing Machinery (ACM) e a International Society for Technology in Education (ISTE) terem normas que direcionam escolas quanto à inserção da Computação e do PC 
VII Congresso Brasileiro de Informática na Educação (CBIE 2018)

Anais do XXIV Workshop de Informática na Escola (WIE 2018)

na educação. No Brasil, a Sociedade Brasileira de Computação (SBC) e iniciativas de universidades, efetuam intervenções destinadas à comunidade com o propósito de disseminar esses conhecimentos. No que tange às ações de campo, quase sempre, essas são efetuadas diretamente pelo profissional da Computação [França et al. 2014, Raabe et al. 2017], sem integração e interação com o professor do Ensino Básico.

Este artigo tem como objetivo relatar experiências de ensino que estimulam o PC, sendo tais atividades desenvolvidas e mediadas por professores do Ensino Fundamental I (EFI). Esta pesquisa, de cunho descritivo, faz parte de uma investigação mais ampla, a qual proporcionou a oferta de uma formação continuada sobre PC. Baseado em um abordagem de investigação qualitativa [Creswell 2014], algumas das práticas desenvolvidas no curso foram acompanhadas pela pesquisadora, a fim de capturar características de ambiente e impressões que ajudassem na descrição dos relatos das experiências de campo. Os professores mostraram-se mais adeptos às atividades desplugadas, além de ser visível a incorporação de diferentes estratégias de ensino para mediar tais práticas.

O artigo está organizado como segue: a Seção 2 apresenta conceitos e trabalhos relacionados ao PC na educação básica; a Seção 3 fornece descrições sobre a metodologia deste trabalho; a Seção 4 exibe o relato de quatro experiências sobre PC acompanhadas; a Seção 5 aborda discussões sobre as observações feitas e a Seção 6 conclui este trabalho.

\section{Iniciativas, Conceitos e Trabalhos Relacionados}

Com o propósito de difundir o PC e fornecer subsídios para a sua implantação no Ensino Básico, iniciativas estrangeiras como o CS Unplugged [Bell et al. 2011] e a Barefoot CAS [Barefoot 2014], fornecem materiais didáticos gratuitos de atividades que estimulam esse raciocínio computacional nas crianças. Há também grupos brasileiros que oferecem cursos e oficinas à comunidade (como o Computação na Escola, o Meninas Digitais, o Computing to You! e o Laboratório de Inovação Tecnológica na Educação), além da própria SBC estar em processo de discussão com representantes da Base Nacional Comum Curricular (BNCC) quanto à adequação da base, para incorporar habilidades sobre o desenvolvimento do PC no currículo [Leite and da Silva 2017, SBC 2017].

Apesar de todas essas ações sobre o tema, ainda não existe um consenso por parte dos pesquisadores da Computação sobre as habilidades que configuram esse "pensar computacional" [Kalelioglu et al. 2016]. Nesse contexto, este trabalho baseou-se nas habilidades do PC estabelecidas por CSTA / ISTE (Computational Thinking Leadership Toolkit), CSTA / ACM (K-12 Computer Science Standards), Barefoot [Barefoot 2014] e a SBC [SBC 2017], sendo elas: Raciocínio Lógico, capacidade de analisar fatos e estruturar ideias para argumentar sobre um problema; Algoritmos / Procedimentos, capacidade de gerar uma sequência finita de instruções para executar uma tarefa; Decomposição / Generalização, capacidade de quebrar um problema em partes menores ou de analisar partes para se chegar no todo; Reconhecer Padrões, capacidade de identificar similaridades entre problemas e aplicá-las a outras situações semelhantes; Abstração, capacidade de sintetizar fatos com o intuito de decidir o que é importante e ignorar detalhes desnecessários; Paralelismo, capacidade de administrar e distribuir recursos para realizar tarefas forma simultânea e colaborativa; e Manipulação de Dados, capacidade de coletar, avaliar e representar dados de maneira objetiva e sistêmica.

Nota-se um aumento no número de pesquisas voltadas tanto para o levanta- 
VII Congresso Brasileiro de Informática na Educação (CBIE 2018)

Anais do XXIV Workshop de Informática na Escola (WIE 2018)

mento do currículo de Computação aplicado à educação [Balanskat and Engelhardt 2015, Kalelioglu et al. 2016], como também relatos de experiências que descrevem o fomento ao PC no Ensino Básico [França et al. 2014, de Campos et al. 2014, Ferreira et al. 2015, Raabe et al. 2017]. Assim, são destacados trabalhos relacionados que abordam algumas dessas intervenções de campo na educação básica brasileira, tais como: a aplicação de práticas desplugadas sobre Ciência da Computação atreladas ao ensino de programação e robótica, efetuadas por licenciandos em Computação entre 2011 e 2013, mediadas em escolas públicas e privadas [França et al. 2014]; as atividades que integraram PC com Matemática, aplicadas por discentes de Ciência e Engenharia da Computação, em turmas de $4^{\circ}$ ano de escolas públicas de periferia [de Campos et al. 2014]; o planejamento e a condução de atividades desplugadas interdisciplinares sobre Computação, efetuadas a partir de intervenção conjunta entre profissionais da Computação e docentes do Ensino Básico, com alunos do Ensino Fundamental II e Médio [Ferreira et al. 2015]; bem como a formação de um laboratório maker que envolveu atividades sobre programação e robótica, contando com a participação de alunos do Ensino Médio e que relata projetos desenvolvidos pelos participantes [Raabe et al. 2017].

Este estudo diferencia-se dos mencionados anteriormente por relatar experiências sobre Pensamento Computacional que foram desenvolvidas e aplicadas por docentes do Ensino Fundamental I, no qual contaram com a participação da pesquisadora como observadora e avaliadora de forma externa, na maioria dos casos. Espera-se que os relatos documentados neste trabalho, e em especial, as reflexões e compreensões obtidas, possam contribuir com a comunidade acadêmica, ao oferecer novas possibilidades de pesquisas no que tange o ensino do Pensamento Computacional na educação básica brasileira.

\section{Metodologia, Procedimentos e Materiais}

A pesquisa descritiva é considerada uma metodologia que visa analisar fatos e/ou fenômenos, a fim de realizar uma descrição em profundidade sobre uma realidade pesquisada. Esse tipo de investigação é abrangente e exige rigor quanto à definição de métodos e técnicas de investigação, sendo conduzido a partir de dados obtidos de estudos exploratórios [Oliveira 2016, p.67]. Para suportar esse tipo de pesquisa científica, tem-se na observação, uma técnica amplamente usada em investigações qualitativas, que visa coletar dados com base no ato de presenciar um fenômeno em campo, com propósitos científicos e apoiado por instrumentos de registro [Creswell 2014, p.137].

Este estudo se enquadra à uma pesquisa descritiva, com o propósito de sintetizar e expor relatos de observações concretizadas em escolas de Educação Básica. Essas narrações descrevem experiências de práticas de ensino relacionadas ao PC, desenvolvidas e conduzidas por professores do EFI, acompanhadas por um profissional da Ciência da Computação (CC). Este artigo também faz parte de um estudo de caso mais amplo, que investiga sobre as possibilidades de inclusão do PC em práticas de ensino direcionadas ao EFI. Nesse contexto, foi ofertada uma formação continuada, com o intuito de capacitar os docentes sobre como integrar esse raciocínio computacional em práticas de ensino, documentadas e aplicadas por professores do EFI. A Figura 1 apresenta a metodologia adotada e as ações empregadas para a obtenção e avaliação dessas práticas de ensino.

Na etapa 1) Formação Continuada foi ofertada à comunidade uma formação continuada sobre PC para atender docentes em exercício no EFI e demais interessa- 
VII Congresso Brasileiro de Informática na Educação (CBIE 2018)

Anais do XXIV Workshop de Informática na Escola (WIE 2018)

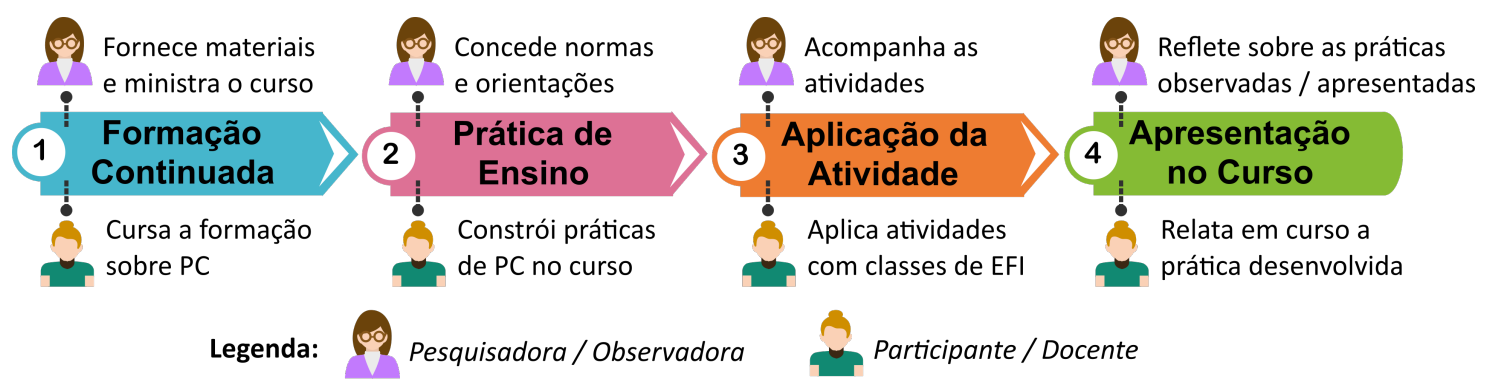

Figura 1. Ações sobre o desenvolvimento deste estudo, mediado por uma investigação descritiva

dos. Diante do número expressivo de 172 interessados, decidiu-se firmar uma parceria entre a Universidade Federal de São Carlos - UFSCar Câmpus Sorocaba (atividade de extensão $n^{\circ}$ 23112.000887/2018-10) e o Instituto Federal de Educação, Ciência e Tecnologia de São Paulo - IFSP Câmpus Itapetininga (atividade de extensão $\mathrm{n}^{\mathrm{o}}$ 287172.1565.143986.17112017) para viabilizar a oferta de duas turmas do mesmo curso, uma em cada entidade, sendo oferecidas 40 vagas por classe. O curso foi ministrado pela própria pesquisadora e aplicado durante o primeiro semestre de 2018. De caráter semipresencial, as 8 aulas presenciais foram ministradas em encontros quinzenais, com duração de 180 minutos cada. Para as 6 aulas de formato EAD foram disponibilizados materiais ${ }^{1}$, vídeos ${ }^{2}$ e suporte online no mesmo dia e horário dos encontros presenciais. Durante o curso, explorou-se o PC nas diferentes áreas de conhecimento, além de apresentar estratégias de ensino como atividades plugadas / desplugadas, Cultura Maker (com a construção de brinquedos e instrumentos ópticos), práticas voltadas para robótica e programação (com kits como o Makey Makey e aplicações como o Scratch e o Code.org) bem como o uso de diferentes Objetos de Aprendizagem (OAs).

A etapa 2) Prática de Ensino representa o desenvolvimento de práticas de ensino que integram o PC aos conteúdos e habilidades exigidas por cada Componente Curricular, em conformidade com a BNCC. A união desses preceitos na elaboração das práticas buscou atender habilidades do Pensamento Computacional e dos Componentes Curriculares, habilidades essas, que o aluno precisaria empregar para resolver um problema proposto. $\mathrm{O}$ desenvolvimento dessas atividades foi requisito de avaliação na formação continuada e ocorreu em dois momentos, que representaram a elaboração de duas atividades de ensino distintas. Para a construção dessas práticas pelos professores, alguns critérios tiveram de ser atendidos, entre eles: i) compor grupos de 3 a 4 pessoas; ii) documentar a ação de ensino em um formato determinado de plano de aula; iii) organizar e produzir artefatos para uso nas práticas, de caráter digital ou não; iv) aplicar a atividade em uma classe do EFI por um ou mais integrantes e, v) efetuar correções no plano de aula de acordo com a experiência, se necessário. É válido pontuar que, entre as duas atividades elaboradas por cada grupo, apenas uma delas tinha a obrigatoriedade de ser aplicada com crianças.

A aplicação dessas práticas entre estudantes do Ensino Básico desencadeia a etapa 3) Aplicação da Atividade, na qual foi empregada a técnica de observação participante, em que a pesquisadora acompanhou as atividades nas escolas onde foram aplicadas, para

\footnotetext{
${ }^{1}$ Acesse a documentação das atividades ministradas na formação em: http://www.c2yensina.ufscar.br

${ }^{2}$ Acesse a playlist das aulas dadas na formação em: http://bit.ly/C2Yplaylist
} 
VII Congresso Brasileiro de Informática na Educação (CBIE 2018)

Anais do XXIV Workshop de Informática na Escola (WIE 2018)

observar a experiência em campo, mas sem intervir nas ações dos docentes e dos alunos durante as práticas. Para essa atuação foi necessário o uso de um protocolo observacional como mecanismo manual de registro, composto por: cabeçalho, como identificador geral sobre a atividade observada; notas descritivas, para retratar informações do ambiente físico, eventos e ações dos envolvidos e notas reflexivas, para descrever hipóteses, impressões e aprendizados por parte do observador [Creswell 2014, p.138].

Apesar de não ter sido possível acompanhar todas as atividades aplicadas, as práticas foram apresentadas pelos participantes em aulas da formação continuada. Essa apresentação, equivalente à etapa 4) Apresentação no Curso, possibilitou a exposição dos planos de aula documentados, dos artefatos produzidos e/ou utilizados nas práticas e forneceu espaço para relatos dos docentes quanto às atividades desenvolvidas pelos grupos.

Ao considerar todos os processos envolvidos neste estudo, para os devidos fins desta pesquisa descritiva, têm-se três elementos centrais vinculados à análise das práticas acompanhadas: i) os protocolos observacionais, documento para anotações livres, estruturado com notas descritivas e reflexivas do ambiente observado; ii) os registros digitais das atividades, compostos por fotos, áudios e vídeos, capturados diante da autorização das escolas visitadas; e iii) os planos de aula, elaborados pelos grupos de professores durante a formação continuada e entregues via ambiente EAD. A avaliação desses documentos ${ }^{3}$ sustentam as seções seguintes, que visam mostrar alguns relatos de experiências e discussões das vivências de campo quanto ao desenvolvimento do PC no Ensino Básico.

\section{Relatos de Experiências das Práticas de Ensino sobre PC}

Das práticas de ensino desenvolvidas por educadores do Ensino Básico, foram selecionadas quatro experiências para serem relatadas nesta seção. A seleção destas priorizou expor atividades que atenderam a diferentes habilidades do PC e Componentes Curriculares distintos. Os relatos estão baseados na observação realizada pela pesquisadora e são descritos em ordem cronológica de aplicação das atividades.

A atividade "Bingo Binário", sobre Matemática (EF02MA05) 4 , teve como objetivo trabalhar a capacidade de reconhecer padrões entre sistemas numéricos distintos (decimal e binário), a partir do desenvolvimento do cálculo mental com adição. Notas Descritivas: Para estimular esse raciocínio entre crianças do $2^{\circ}$ ano, junto ao tema de Computação incorporado, foi projetado para a dinâmica um tapete de 15 espaços ocupados por um padrão binário de quatro bits e com sequências distintas de símbolos $(\mathbf{O}=0 \mathrm{e}$ $\boldsymbol{Y}=1$ ), um cartaz com informações sobre a posição binária e o valor decimal de cada bit, e bolinhas numeradas entre 1 e 15 . Inicialmente, a professora revisou conceitos sobre o que é um sistema binário e dá exemplos de aplicação no cotidiano, utilizando esse modelo. Depois, com a classe divida em dois grupos, a docente sorteava um número, e as equipes tinham 30 segundos para avaliarem qual sequência binária do tapete seria equivalente ao decimal para, em seguida, um dos membros do grupo pisar em um espaço-alvo. O primeiro discente a pisar na sequência explica aos demais como o grupo chegou no resultado (soma das posições com $\vee$ ). Após várias rodadas, o grupo com mais pontos vencia a gincana. Notas Reflexivas: Entre 20 rodadas feitas, próximo da décima, foi retirado o cartaz de apoio, uma vez que a docente nota que os alunos estavam conseguindo identificar as

\footnotetext{
${ }^{3}$ Acesse os modelos de protocolo observacional e de plano de aula em: http://bit.ly/T1_WIE2018

${ }^{4}$ A seção exibe códigos de habilidades dadas pela BNCC. Consulte o documento para mais informações.
} 
VII Congresso Brasileiro de Informática na Educação (CBIE 2018)

Anais do XXIV Workshop de Informática na Escola (WIE 2018)

sequências binárias com facilidade. Os alunos resolveram cada rodada, em média, na metade do tempo fornecido (15 segundos), e se mostraram motivados e entusiasmados com a atividade. A prática propiciou um ambiente colaborativo e apontou o uso de estratégias como Gamificação, por usar pontuação e proporcionar desafios; além do uso de Objetos de Aprendizagem, como o tapete e o cartaz criados pelos professores envolvidos.

Já a atividade "Localização por Coordenadas", sobre Geografia (EF02GE10), teve como propósito a construção de algoritmos/procedimentos por parte das crianças, para que elas aplicassem conhecimentos sobre coordenadas, localização, movimentação e orientação, mediados pela rosa dos ventos. Notas Descritivas: O cenário da atividade foi composto por um tapete de TNT com quadrados coloridos e impressões em A3 de diferentes locais (escola, parque, hospital, restaurante, etc). Esta atividade contou com a participação de duas classes do $4^{\circ}$ ano, sendo cada classe, uma equipe. A partir de diversas missões, como 'sair da escola e chegar até o hospital', e com comandos determinados pelas direções da rosa dos ventos, as equipes projetaram seus algoritmos definindo o número de passos para cada direção. Uma vez montado o algoritmo, o mesmo era executado por um membro da equipe, sendo este depurado com a ajuda das professoras e dos demais colegas. Como regra, as equipes tinham que organizar algoritmos diferentes sobre uma mesma missão. Notas Reflexivas: Como essa prática atendeu em torno de 50 alunos, na tentativa de fazer a maioria das crianças participarem, foram feitas muitas rodadas, tornando a atividade um pouco cansativa aos discentes. Mesmo mediada por dois docentes, seria viável reorganizar a dinâmica em grupos com menos alunos e estruturá-la de forma que não fosse necessário todas as crianças atuarem no tapete. Uma sugestão para tornar cada rodada mais desafiadora, seria trocar os locais nos pontos do tapete. Os OAs desenvolvidos pelas professoras para a dinâmica foram doados à escola, uma vez que outros docentes se interessaram pela prática.

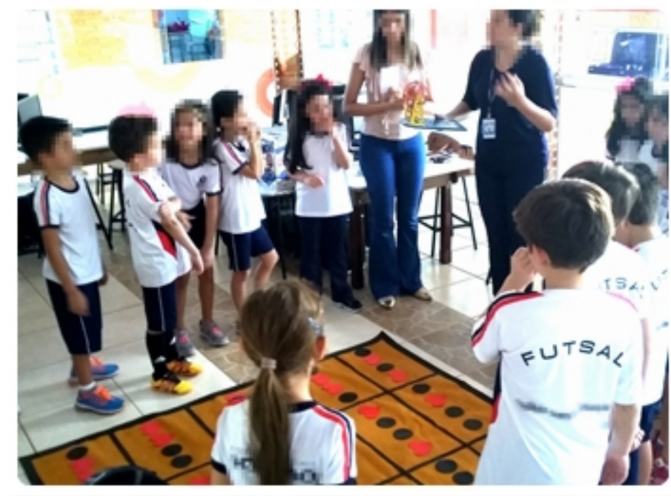

Foto A - "Bingo Binário"

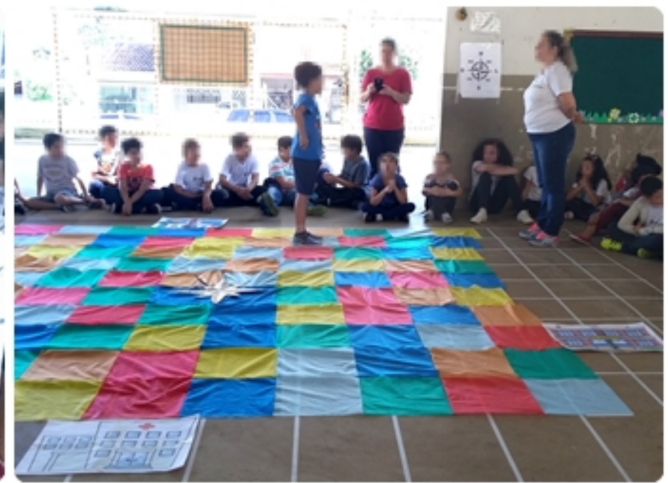

Foto B - "Localização por Coordenadas"

Figura 2. Registros das atividades descritas nos dois primeiros relatos

A prática "Desafios no Scratch", relacionada à Matemática (EF03MA08), trabalhou a interpretação e a manipulação de dados, a fim de organizar termos-chave (comandos) em categorias, para posterior montagem de procedimentos usando o Scratch. Notas Descritivas: em trios, os alunos do $3^{\circ}$ ano receberam cartões com um algoritmo no formato de texto instrucional. No texto, os termos em destaque correspondem aos comandos do Scratch. Os alunos receberam também um guia que mostra todos os comandos de cada categoria, de acordo com o Scratch. Na etapa desplugada, as crianças identificaram a ca- 
VII Congresso Brasileiro de Informática na Educação (CBIE 2018)

Anais do XXIV Workshop de Informática na Escola (WIE 2018)

tegoria de cada um dos termos em destaque no algoritmo fornecido. Essa organização de dados auxilia as equipes para a etapa plugada, onde os grupos se reúnem com a docente frente a lousa digital, para construírem os códigos, a partir do algoritmo e dos comandos categorizados. Notas Reflexivas: Durante a observação, a professora relata que a ideia inicial era conduzir a prática no laboratório de informática, mas que o mesmo se encontrava em manutenção desde 2017. Havendo apenas um computador para uso dos alunos, seria interessante que cada trio programasse no Scratch, individualmente, uma missão, para, dessa forma, ter o envolvimento de todos os discentes. Mesmo assim, os alunos ficaram entusiasmados, especialmente na etapa plugada da atividade. Essa prática também retratou um caso particular, ao usar uma estratégia de ensino voltada para Programação.

E a atividade "Investigando Solos", aplicada em uma escola rural e relacionada com Ciências (EF03CI09), promoveu o desenvolvimento da habilidade de abstração por meio da análise e comparação de diferentes amostras de solos, com o intuito de identificar características entre eles. Notas Descritivas: A atividade usa três amostras de solos, um computador, um projetor e outros materiais diversificados. As professoras fazem uma introdução sobre o que é o Pensamento Computacional e mostram um vídeo de exemplo. É exibido um segundo vídeo, que instrui os alunos sobre como montarem um microscópio caseiro com um smartphone, uma lente de webcam e massinha de modelar. Os alunos são então divididos em dois grupos, e cada equipe fica responsável por montar um microscópio para uso colaborativo. Com os dispositivos montados, cada docente conduz um grupo na observação dos solos, que durou aproximadamente 15 minutos. Durante a análise, as professoras argumentavam sobre propriedades desses solos, além de tirarem fotos, sendo elas impressas na secretaria da escola. Na etapa desplugada, cada criança recebe uma ficha de observação para experimentos (fornecida no curso de formação continuada), para que eles registrem características de composição dessas amostras (cor, textura, cheiro, tamanho das partículas, etc.) e colem uma foto de cada amostra descrita. Notas Reflexivas: A prática despertou o interesse e a atenção dos alunos, especialmente na fase de observação das amostras. Ao acompanhar os grupo nas observações, percebese a facilidade dos alunos em fazer relações entre o conteúdo abordado e o cotidiano dos estudantes. Essa prática foi uma das poucas que incorporaram a Cultura Maker como estratégia de ensino, na primeira etapa da prática, além dos próprios OAs.

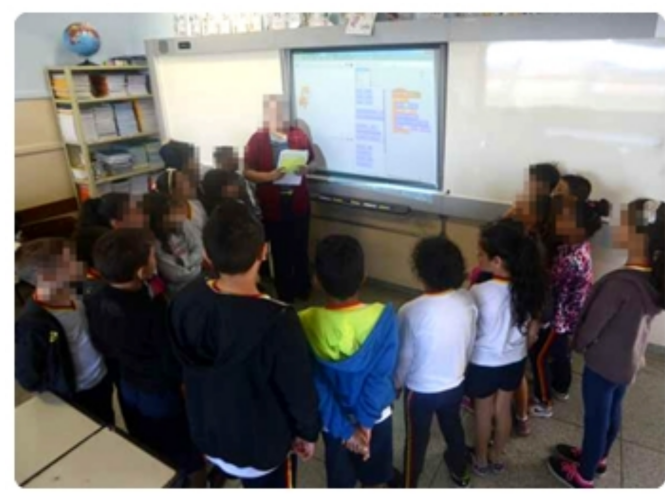

Foto C - "Desafios no Scratch"

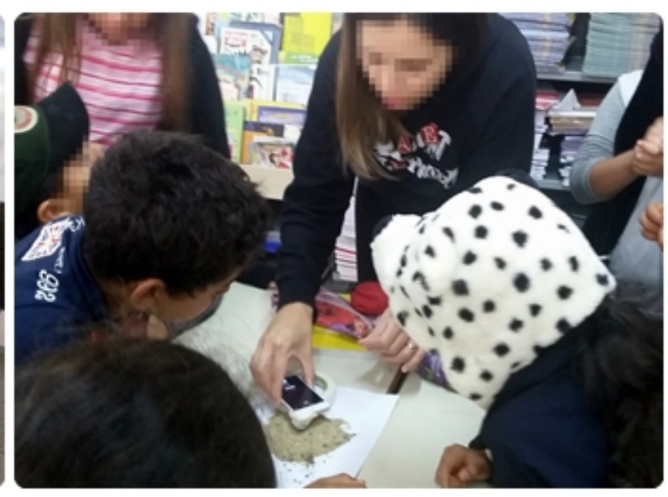

Foto D - "Investigando Solos"

Figura 3. Registros das atividades descritas nos dois últimos relatos 
VII Congresso Brasileiro de Informática na Educação (CBIE 2018)

Anais do XXIV Workshop de Informática na Escola (WIE 2018)

\section{Outras Práticas de Ensino e Discussões}

Com 26 docentes concluintes em cada uma das turmas da formação continuada e totalizando 52 participantes, foram recebidas 33 atividades ${ }^{5}$ de ensino documentadas (planos de aula), aos quais 21 dessas foram aplicadas no EFI e 13 contaram com a presença da pesquisadora (observação participante). Das práticas documentadas e aplicadas, 17 escolas distintas foram atendidas (70,5\% entre as instituições públicas e $29,5 \%$ colégios privados) por experiências que estimularam o raciocínio computacional em crianças do EFI, distribuídas entre três municípios do interior do estado de São Paulo, sendo eles Alambari, Itapetininga e Sorocaba.

A análise dos protocolos observacionais, dos registros digitais das práticas acompanhadas, dos planos de aula obtidos de todas atividades documentadas, e de relatos pessoais feitos pelos participantes ao longo da formação continuada, possibilitou discutir sobre alguns aspectos. Cada argumento é destacado por uma afirmação (impressão da pesquisadora), seguido de colocações que sustentam essa interpretação.

"A maioria dos docentes optaram por atividades de caráter desplugado": os participantes justificaram que a escolha desse formato se deu por se sentirem mais confiantes quanto à organização e mediação de uma prática que, de fato, conseguisse estimular o PC, mesmo nos casos em que as escolas tinham recursos digitais. Todavia, o aumento de práticas plugadas desenvolvidas na segunda avaliação, mostra que os docentes passaram a se sentir mais seguros no uso de recursos ou Objetos de Aprendizagem digitais.

"Poucas práticas integraram um tema/assunto específico da Computação": somente sete, das 33 atividades produzidas, envolveram assuntos próprios da CC. Entre essas sete atividades, duas delas abordaram sobre sistema binário e outras duas, redes de computadores. As demais, trataram ordenação por bubble-sort, grafos e composição de imagens por pixels. De acordo com as observações feitas e com os relatos dos participantes, mesmo em classes do início do EFI, as crianças demonstram facilidade em resolver problemas, a partir de influências ou regras baseadas em temas da Computação, e mostram-se entusiasmadas com esse tipo de abordagem.

"A necessidade da composição de grupos com um docente do EFI para a troca de conhecimentos": alguns grupos foram afetados pela evasão de alguns professores na primeira avaliação. Grupos que permaneceram com pelo menos um docente do Ensino Básico conseguiram organizar e administrar facilmente práticas de PC, até mesmo, incluindo assuntos de Computação. Porém, equipes que permaneceram com integrantes de outras áreas, somente da Computação ou sem qualquer experiência no Ensino Básico, tiveram dificuldades. Essa complexidade foi vista na documentação da prática, em abstrair como a atividade seria com as crianças, e principalmente na condução da atividade, ao qual várias variáveis saíram do planejamento feito anteriormente.

"Uma prática com foco em uma habilidade do PC possibilita o desenvolvimento de outras habilidades por parte das crianças": ao planejar e aplicar uma atividade sobre PC, com foco em uma concepção, a criança pode ter que desempenhar outras habilidades que compõe esse "pensar computacional". Isso foi percebido também pelos professores, ao longo do curso, de acordo com o envolvimento destes na produção das atividades. A média de concepções, atendidas por cada prática, ficou em torno de três habilidades.

\footnotetext{
${ }^{5}$ Para consultar dados gerais sobre as atividades dos participantes, acesse: http://bit.ly/T1_WIE2018
} 
VII Congresso Brasileiro de Informática na Educação (CBIE 2018)

Anais do XXIV Workshop de Informática na Escola (WIE 2018)

Mesmo uma determinada prática podendo ser classificada em mais de uma concepção do PC, a escolha de apenas uma habilidade facilitou para os grupos estruturarem atividades que realmente estimulassem o raciocínio computacional.

"Estratégias de ensino distintas e ambientes/cenários diferentes do cotidiano do aluno fomentam o raciocínio computacional": entre todas as estratégias de ensino empregadas na formação continuada, a Gamificação e os OAs foram as mais usadas pelos professores nas atividades com as crianças. Por incorporar essas estratégias, elementos como a separação dos alunos em grupos, regras, pontuação e rankings foram quase sempre aplicados nas atividades. Uma abordagem que não foi utilizada pelos participantes, foi a robótica educacional, o que, provavelmente, se justifica por apenas três professores de escolas privadas terem acesso a kits para atuarem com essa técnica. Uma estratégia que não foi abordada em curso, mas se mostrou presente em três práticas documentadas é a Aprendizagem Baseada em Problemas. Atividades que usaram dessa técnica, deram foco em habilidades como Manipulação de Dados, Paralelismo e Decomposição / Generalização, além de envolver os alunos em um processo de criação e autonomia.

"Os docentes relatam possibilidades de como estimular o Pensamento Computacional no Ensino Infantil": ao longo do curso, em vários momentos entre as práticas efetuadas em aula e nas apresentações dos docentes sobre as atividades elaboradas em grupo, docentes com experiência ou em atuação no Ensino Infantil, indicavam sugestões de adaptações das práticas para esse público, além de relacionarem como o PC poderia ser estimulado. A maioria dessas sugestões ao contexto infantil atendiam a habilidades como Reconhecer Padrões e Decomposição / Generalização.

\section{Considerações Finais}

Este artigo apresentou relatos de experiências e discussões sobre práticas de ensino relacionadas ao Pensamento Computacional, desenvolvidas e aplicadas por docentes do Ensino Fundamental I, a partir de uma formação continuada. Com base em uma pesquisa descritiva e apoiada pela técnica de observação participante, a pesquisadora pôde ter algumas percepções e vivências de como o professor do Ensino Básico visualiza a relação entre o PC e os demais Componentes Curriculares, e como essa associação é empregada em práticas de ensino que engajem as crianças.

Apesar de ser um assunto desconhecido aos professores que fizeram o curso, ao final da formação, eles declararam que esse "pensar computacional" é algo intrínseco em suas práticas educacionais, e que o esclarecimento sobre esse conjunto de habilidades facilitou a maneira de estimulá-las nos discentes. Mesmo porque, o fomento a essa competência independe dos recursos digitais oferecidos pela escola. É claro que, softwares, kits de robótica e computadores, enriquecem muito a experiência dos alunos; porém, a falta deles nas escolas não impede o docente de propiciar práticas motivadoras, que desenvolvam o raciocínio analítico e sistemático do aluno. Para novas possibilidades de pesquisa, estudos que abordem sobre o PC na Educação Infantil têm potencial de investigação, uma vez que essa conexão foi reforçada por participantes da formação.

Acredita-se que este estudo também conseguiu atingir ao tripé que rege o processo de ensino-aprendizagem das instituições federais brasileiras, constituído pelo ensino, a pesquisa e a extensão. A partir de investigações coletivas desenvolvidas por membros do Computing to You! (C2Y!), este estudo, em particular, promoveu a interação da universi- 
VII Congresso Brasileiro de Informática na Educação (CBIE 2018)

Anais do XXIV Workshop de Informática na Escola (WIE 2018)

dade com a população e a difusão do conhecimento produzido na academia entre docentes do Ensino Básico, de maneira prática e aplicável no cotidiano. Agradecimentos à CAPES, as escolas que permitiram a visita da pesquisadora, ao Prof. Me. Wilton Moreira Ferraz Jr. (IFSP Câmpus Itapetininga), e aos alunos Maylon P. Macedo e Yuri S. Padua (C2Y!).

\section{Referências}

Balanskat, A. and Engelhardt, K. (2015). Computing our future: Computer programming and coding. Priorities, school curricula and initiatives across Europe. European Schoolnet.

Barefoot (2014). Primary Computing Resources - Concepts: Computational Thinking. Disponível em: [https://barefootcas.org.uk]. Acesso em: 19/07/2016.

Bell, T., Witten, I. H., and Fellows, M. (2011). Computer Science Unplugged: Ensinando Ciência da Computação sem o uso do computador. CSUnplugged. Traduzido por Luciano Porto Barreto.

Creswell, J. W. (2014). Investigação Qualitativa e Projeto de Pesquisa: Escolhendo entre Cinco Abordagens. Penso Editora, $3^{a}$ edition.

de Campos, G. M., Cavalheiro, S., Foss, L., Pernas, A. M., de Brum Piana, C. F., Aguiar, M., Du Bois, A., and Reiser, R. (2014). Organização de informações via pensamento computacional: Relato de atividade aplicada no ensino fundamental. In Workshop de Informática na Escola, 390-399.

Ferreira, A. C. C., Melhor, A., Barreto, J. d. S., de Paiva, L. F., and Matos, E. (2015). Experiência prática interdisciplinar do raciocínio computacional em atividades de computação desplugada na educação básica. In Workshop de Informática na Escola, 256-265.

França, R., Ferreira, V., de Almeida, L., and do Amaral, H. (2014). A disseminação do pensamento computacional na educação básica: lições aprendidas com experiências de licenciandos em computação. In Workshop sobre Educação em Computação, 14731482 .

Kalelioglu, F., Gülbahar, Y., and Kukul, V. (2016). A framework for computational thinking based on a systematic research review. Baltic Journal of Modern Computing, 4(3). 583-596.

Leite, M. and da Silva, S. F. (2017). Redimensionamento da computação em processo de ensino na educação básica: O pensamento computacional, o universo e a cultura digital. In Workshop da Licenciatura em Computação, 804-813.

Oliveira, M. M. d. (2016). Como Fazer Pesquisa Qualitativa. Editora Vozes, $7^{\text {a }}$ edition.

Raabe, A., Metzger, J., Gomes, E., Vieira, M. V., Santana, A. L. M., Souza, F. T., Ramos, G., and Cucco, L. (2017). Características do pensamento computacional desenvolvidas em aprendizes do ensino médio por meio de atividades makers. In Workshop de Informática na Escola, 145-154.

SBC (2017). Computação na educação básica (versão preliminar). XXXVII CSBC. Disponível em: [https://goo.gl/NNdUv9]. Acesso em: 20/07/2017.

Wing, J. M. (2006). Computational thinking. Communications of the ACM, 49(3):33-35. 